[This is a draft of a paper that appeared in Julian Dodd and Helen Beebee (eds.) Truthmakers: The Contemporary Debate (Oxford: Oxford University Press 2005), pp. 105-115.]

\title{
Truthmakers and explanation
}

\author{
David Liggins
}

Truthmaker theory promises to do some useful philosophical work: equipping us to argue against phenomenalism and Rylean behaviourism, for instance, and helping us decide what exists (Lewis 1999, 207; Armstrong 1997, 113-119). But it has proved hard to formulate a truthmaker theory that is both useful and believable. I want to suggest that a neglected approach to truthmakers - that of lan McFetridge - can surmount some of the problems that make other theories of truthmaking unattractive. To begin with, I'll outline some of the most prominent accounts of truthmaking in the current literature. Then the second part of the paper will explain McFetridge's theory and argue for its superiority over these accounts.

\section{$1 \quad$ Truthmaking as supervenience}

\section{$1.1 \quad$ Current truthmaker theories}

A philosophical naturalist is likely to claim that our best explanatory theories can be used to determine what exists. But how is this to be done? One way of attacking the problem is to use the notion of ontological commitment. By this I mean the following:

OC A proposition $p$ is ontologically committed to an entity $e$ iff $p$ entails that $e$ exists.

(I will ignore Quinean worries about propositions.) OC is supposed to be a way of drawing out what a theory says about what exists. To find out what existential claims a theory makes, we run through its assertions and note down their ontological commitments. In this way we can have empirical evidence for existence claims, admitting entities to our ontology for 'essentially scientific reasons' (Quine 1969, 97). Ontological commitment thus ties together theory and ontology. For instance, suppose you are offered a package: a theory and an ontology to go with it. Suppose that the ontology you are offered is leaner than the ontological commitments of the 
theory. Then you must reject the theory-ontology pair. The theory says that there is more in the world than the ontology admits to, so together they form an inconsistent package.

Truthmaker theories also offer constraints on theory-ontology pairs. The simplest theory on the market is Armstrong's:

A If a proposition $p$ is true then there exists an entity $e$ such that $<e$ exists $>$ entails that p. (Armstrong 1997, 115).

Here 'entails' has its usual meaning: A entails B iff there is no possible world where A holds but B fails. An entity $e$ whose existence entails that $p$ is said to be a truthmaker for $p$.

It is easy to see how A acts as a constraint on theory-ontology pairs. If you assert a theory which claims that $p$ whilst accepting Armstrong's principle, then on pain of inconsistency your ontology must contain a truthmaker for $p$. According to Armstrong, any theory which includes a proposition but provides no truthmaker for it in its ontology is contravening the truthmaker principle.

Armstrong claims that all truths have truthmakers (Armstrong 1997, 135). This attitude seems very strange when applied to negative existential truths like 'There are no giant pandas in Sheffield'. What entity could there be whose existence would entail the truth of this claim? It would have to be an 'anti-panda': something that exists just when there are no giant pandas in Sheffield. I find it more natural to think that statements like this 'are true not because things of some kind do exist, but rather because counterexamples don't exist' (Lewis 1999, 204). This suggests that negative existential truths don't need truthmakers.

One way of modifying Armstrong's theory is to exclude negative existentials from the scope of his truthmaker principle. But that seems too drastic. It is not that there is no link between truth and ontology for negative existential truths; rather, the link is of a different sort. In Lewis's words, they are 'true for lack of false-makers' $(1999,204)$. These thoughts spur Bigelow to revise Armstrong's theory. According to Bigelow, '[i]f something is true, then it would not be possible for it to be false unless certain things were to exist which don't, or else certain things had not existed which do' $(1988,133)$. Taking 'certain things' to mean 'one or more things', this 
becomes

B For any proposition $\mathrm{P}$ and any worlds $\mathrm{W}$ and $\mathrm{V}$, if $\mathrm{P}$ is true in $\mathrm{W}$ but not in $\mathrm{V}$, then either something exists in $\mathrm{V}$ but not in $\mathrm{W}$ or else something exists in $\mathrm{W}$ but not in $\mathrm{V}{ }^{1}$

Bigelow sums up his theory in the claim that 'truth is supervenient on being' $(1988,132)$.

Bigelow's view entails that the only differences between possible worlds are existential ones, a feature which David Lewis thought counterintutive. Could there not could be two different possible situations where exactly the same things exist, differing simply in what properties they have? This thought led Lewis to assert that

$\mathrm{L} \quad$ For any proposition $\mathrm{P}$ and any worlds $\mathrm{W}$ and $\mathrm{V}$, if $\mathrm{P}$ is true in $\mathrm{W}$ but not in $\mathrm{V}$, then either something exists in one of the worlds but not in the other, or else some $n$-tuple of things stands in some fundamental relation in one of the worlds but not in the other. (Lewis 2001, 612.)

Lewis suggests that principle L distils what is right in truthmaker theory $(1999,224,206-7)$. Josh Parsons also hints at a theory like this when he suggests that 'every true sentence's truth supervenes on the nature of some thing' $(1999,327)$.

It should be clear that the theories of Bigelow and Lewis act as constraints on theory-ontology pairs. Principles B and $L$ are both conditional in form: in each case, the first part talks about what is true in which world, and the second part talks about what exists or what properties it has. For Bigelow and Lewis, truths have ontological implications.

Before we see these theories at work, I should note that some philosophers think that some of these views do not merit the name 'truthmaker theory' at all. For instance, Dodd (2002, 74 n. 9) denies that Parsons' theory deserves to be called this; Lewis (2001) seems unsure whether his does. Dodd also thinks that McFetridge's theory (explained below) shouldn't count

\footnotetext{
${ }^{1}$ I have taken this formulation from Lewis 2001, 610.
} 
as a truthmaker theory $(2000,16 \mathrm{n} .10)$. I am suspicious of any claim to have found the 'true meaning' of a term of philosophical art like 'truthmaker', but the issue is unimportant anyway. Irrespective of what we call these principles, they promise to deliver philosophical results, and that is why they are worthy of our attention. Let us turn to see how these principles can be used in philosophical arguments.

\subsection{Truthmaker theory in action}

One important application of truthmaker theory has been in opposing phenomenalism. I will take phenomenalism to be a thesis about the meaning of sentences about physical objects coupled with an ontological thesis. Phenomenalists claim that sentences about physical objects should be analysed as conjunctions of counterfactuals about experience. These counterfactuals are not made true by physical objects, as we conceive of them, for according to phenomenalists no such physical objects exist. Nor are they ontologically grounded in the properties of human minds - that would be to confuse phenomenalism with idealism. But phenomenalism is not an error theory: sentences about physical objects are often true. Whilst from some epistemological perspective phenomenalism has its advantages, there is something unsatisfying about it which truthmaker theorists seek to exploit. One philosopher goes so far as to accuse phenomenalists of 'ontological murder' (Armstrong 1993, 187).

How can we use truthmaker theory to argue against phenomenalism? Take a true sentence, $\mathrm{P}$ say, concerning a physical object. Suppose that $\mathrm{C}$ is a counterfactual which forms one conjunct in the phenomenalist analysis of $\mathrm{P}$. Then $\mathrm{P}$ entails $\mathrm{C}$, and so $\mathrm{C}$ is true. On Armstrong's theory, $\mathrm{C}$ is committed to the existence of some truthmaker for itself. But the truthmaker cannot be a physical object as we ordinarily conceive them; neither can it be a human mind. To take either of these lines would be to abandon phenomenalism in favour of realism or idealism. So the phenomenalist is beggared to explain just what in the world serves to make the counterfactual true. The truthmaker principle has detected a mismatch between theory and ontology, and condemns phenomenalism on the strength of it. And we can run the argument just as well using Lewis's or Bigelow's theory. The phenomenalist will be unable to name an entity on whose existence the truth of the counterfactual supervenes. Neither will it be 
possible to name a property whose instantiation is linked in the appropriate way to the counterfactual's truth. For what entity would display this property? Phenomenalism dispenses with any candidates. (Compare Armstrong 1989a, 8-10; Lewis 1999, 207.)

It is easy to mount parallel arguments against Gibert Ryle's brand of behaviourism: the view which says that truths about the mind can be analysed as conjunctions of counterfactuals about behaviour, but that these dispositions have no 'categorical bases', that is, that there are no mental properties underlying them. As Parsons $(1999,327)$ says, 'If my beliefs were Rylean dispositions, I could cease believing something without any real change taking place in me or indeed anywhere in the world'. This possibility is just what truthmaker theory rules out.

\subsection{Justifying supervenience theories}

We have seen one way of using truthmaker theory to get philosophical results. But why should we trust this sort of thinking? Armstrong does little to persuade his readers that his truthmaker principle is right: he says that it seems 'fairly obvious once attention is drawn to it' (1989b, 89), but admits that he has no argument to offer. Bigelow also looks to intuition to support his theory: 'I have sometimes tried to stop believing in the Truthmaker axiom. Yet I have never really succeeded' $(1988,123)$. He offers a justification of his view, which has been forcefully criticised elsewhere (Dodd 2002, 79-81). Armstrong and Bigelow have nothing more powerful to offer those of us who, like Alex Oliver, worry that the explanation of truth making in terms of necessitation is richer and more controversial than anything supplied by common sense' (Oliver 1998, 539).

The difficulty of justifying Armstrong and Bigelow's theories has sometimes inspired gloom about the prospects for a defensible theory of truthmakers. ${ }^{2}$ But it seems that we might be able to justify Lewis's version of truthmaker theory using premises that are much harder to reject. According to Lewis, we can know a priori that $L$ is true. Elsewhere he suggests an argument for $\mathrm{L}$, based on a deep-seated intuition about aboutness. According to Lewis,

\footnotetext{
${ }^{2}$ For example, Dodd 2002 argues that there is no good reason to accept B, and concludes that future research into truthmakers is 'pointless' (70 n. 2).
} 
Armstrong's theory is 'an over-reaction to something right and important and under-appreciated. What's right, roughly speaking, is that truths must have things as their subject matter' $(1999,206)$. Here 'a proposition is about a subject matter... iff the truth-value of that proposition supervenes on that subject-matter' $(1998,112)$. Put together, these claims offer an interesting argument for Lewis's theory:

(1) All truths have entities as their subject matter.

(2) For any proposition $p$ and subject matter $M, p$ is about $M$ iff $p$ 's truth-value supervenes on the existence and nature of $\mathrm{M}$.

Hence

(3) For any true proposition $p$, there exists an entity $M$ such that $p$ 's truth-value supervenes on the existence and nature of $\mathrm{M}$.

(By 'the nature of M' I mean 'which properties M has'. M might be a collection of entities rather than an entity in its own right, but the structure of the argument would be unaffected by this change.) Now (3) is just L. So have we found an argument which makes a useful truthmaker theory believable?

\subsection{Supervenience and necessary truths}

This attempt to justify truthmaker theory provokes two worries. Firstly, we might think that (1) is less than obvious, for perhaps logical truths are not about things. But a defender of the argument could ask what advantages that view has over the belief that logical truths are about everything. Since it is difficult to decide whether the subject matter of logical claims is really nothing, or just nothing in particular, I will grant for the sake of argument that a Lewisian could reply to the objection in this way.

The second worry is that Lewis's definition of aboutness (2) does not capture the way that word is usually used. Let $p$ be a necessary truth. Then, because necessities are entailed by all truths, p's truth-value trivially supervenes on the existence and nature of any entity. But would we want to say that necessary truths are about everything? 
We might in some cases. For instance, we have just conceded that the laws of logic might be about everything. But suppose that 'All vixens are foxes' is necessary. It seems to concern vixens rather than penguins or lightbulbs. Philosophers of religion have often taken 'God exists' to be either necessary or impossible without feeling they have to claim that its subject matter is anyone apart from God. The philosophy of mathematics furnishes some counterexamples as well. Many platonists have held the existence of numbers to be necessary; ${ }^{3}$ but they have not denied that arithmetical propositions (for instance) concern numbers alone. And it would seem objectionably ad hoc to ask them to give this up.

I conclude that (2) does not have the obviousness it requires if Lewis's argument is to succeed. This is by no means a devastating objection: the argument could be rescued by weakening the 'iff' in (2) to 'only if'. But these thoughts might inspire scepticism about whether the argument's conclusion really captures all that is of value in truthmaker theory. For just the same reasoning will tell us that any necessarily true proposition will satisfy $L$ irrespective of the ontology it is coupled with. And this seems far too easy. If arithmetical propositions are true in virtue of the necessary existence of numbers and the relations in which they necessarily stand, then it is not trivial at all that these statements are true. Surely a platonist should say that their truthmakers are not just any entities, but some entities connected with the the abstract objects they concern: numbers themselves (whatever sorts of entities they are) or states of affairs concerning numbers, or numbers and the universals they instantiate, or number properties perhaps - but not just anything.

Another way to put the worry is this: Lewis's truthmaker principle does not act as a constraint on theory-ontology pairs in the way we would like it to. Contingent existential claims must have truthmakers: we cannot say that 'There is a penguin in world $W$ ' is true unless there is a penguin in our ontology for world W. And Lewis's supervenience principle requires this, in effect. But suppose we claim that penguins necessarily exist. Surely that means we should say that there is a penguin in the ontology of each world. But Lewis's principle is powerless to

\footnotetext{
${ }^{3}$ Though platonists convinced by the Quine/Putnam indispensability arguments might not, e.g. Colyvan 2001.
} 
enforce this requirement. $L$ begins 'for any proposition $P$ and any worlds $W$ and $V$, if $P$ is true in $\mathrm{W}$ but not in $\mathrm{V}$, then .... Given that $\mathrm{P}$ is necessary, the antecedent of this material conditional will always be false, so $L$ will be satisfied irrespective of what exists. Hence necessary truths satisfy $L$ merely in virtue of their modal status; you can make any existential claim you like without facing its ontological consequences provided you say your claim is necessary. For all $\mathrm{L}$ says, it could be true that there necessarily exist penguins even if there were no penguins at all in any possible world. ${ }^{4}$

Bigelow's principle begins in the same way as Lewis's, so the argument we have just given indicts his theory as well. Indeed, it indicts any theory that takes this form.

Armstrong's theory has a different structure but suffers from a related problem: it is well known that according to A any entity can serve as truthmaker for a necessary truth. As Greg Restall puts it: "Why should my refrigerator count as a truthmaker for the Goldbach conjecture (or its negation)?' (Restall 1996, 334). In short, none of the supervenience theories of truthmaking deals correctly with necessary truths.

\section{McFetridge: truthmaking and explanation}

\subsection{McFetridge on truthmakers}

Seeing the problems that supervenience theories of truthmaking face, several authors have concluded that no truthmaker theory that relies on classical logic can succeed (e.g. Restall 1996, 336). Instead, we need to use 'more finely-honed tools' (Gregory 2001, 427). McFetridge's theory accepts this, invoking the notion of explanation. It is easy to see that this is a more discriminating relation than entailment: that ' $2+2=4$ ' is true is entailed by every truth (assuming arithmetical truths to be necessary), but, crucially, it not explained by every truth. Knowing that Sheffield is in Yorkshire, for instance, doesn't help at all in explaining why it's true that $2+2=4$. We will return to this point later.

McFetridge introduces his theory by considering the question 'What makes a statement true?'. He criticises Davidson's claim that this is merely a confused variant of 'What is it for a

\footnotetext{
${ }^{4}$ Lewis recognises this problem (Lewis 2001, 604).
} 
statement to be true?' (McFetridge 1977, 37-39). McFetridge points out that correspondence theorists of truth have seen themselves as telling us what makes statements true. The answer, according to Russell and Austin, is facts. However, we cannot answer 'What is it for a statement to be true?' with 'A fact'. As McFetridge says, this is 'gibberish' $(1977,38)$.

To unpack this a little, consider the question 'What makes "The apple is red" true?', to which the correspondence theorists' reply is 'The fact that the apple is red'. If the question could be paraphrased into 'What is it for "The apple is red" to be true?', then the correspondence theorists would be saying that what it is for that sentence to be true is a fact. And that doesn't make sense: we cannot answer 'What is it for "The apple is red" to be true?' by giving the name of an entity.

To ask for the truthmaker of a statement, then, is not to ask for an explication of the concept truth as applied to that statement. So what does the demand for a truthmaker amount to? McFetridge considers exchanges of the following form:

'What makes the (English) sentence "Snow is white" true?' 'The fact that snow is white.'...

'What makes the (English) sentence "Grass is green" true?' 'The fact that grass is green.' $(1977,38)$

He immediately goes on to claim that

these questions, and their generalisation into 'What makes a (any) sentence true?' are not requests for definitions (etc.) of 'true' (the concept of truth etc.); but rather requests for (partial) explanations of why certain particular sentences are true. $(1977,38-9)$

Seen in this light, the idea that a statement is true only if it has a truthmaker turns into the following principle:

E For every sentence which is true there must be some explanation of why it is true. 
(McFetridge 1977, 42)

I suggest that McFetridge's reasoning here is not wholly convincing. We can grant that truthmaker theory isn't a way of analysing the concept truth without having to concede that requests for truthmakers are requests for explanations. Armstrong, for example, would agree that truthmaker theory doesn't seek to define 'true ${ }^{, 5}$ but maintain that a request for a truthmaker is not a request for an explanation, but rather a request for an entity whose existence entails that the statement in question is true. The exchanges McFetridge considers could well be understood in this fashion. I agree with McFetridge (1977, 39) that explanation-seeking questions beginning 'What makes...' are most naturally answered by a reply beginning 'The fact that.... But this fails to prove that requests for truthmakers are explanation-seeking questions. Thus the shift from explication to explanation is under-motivated.

I am not going to consider repairs to McFetridge's argument. Even if it cannot be derived through thinking about the question 'What makes a statement true?', McFetridge's principle (E) is, I claim, powerful enough to do some of the work that the supervenience theories can. I will argue for this in section 2.3. It also overcomes their difficulties with necessary truths (section 2.4). And, just as importantly, it is plausible.

\subsection{The plausibility of McFetridge's principle}

I am not sure how to argue for E; I hope no argument is needed. Whilst E's utility in truthmaker theory has been neglected, the truth of $E$ has often been recognised. For instance, Paul Horwich $(1998,104)$ calls it 'undeniable' - he identifies it as the intuition motivating correspondence theories of truth - and Crispin Wright thinks it 'platitudinous' (1992, 25; see also 27). Its scope clearly extends without problem to negative existentials, an advantage of McFetridge's theory over Armstrong's.

One way of motivating the principle is to appeal to the intuition that much of our language is used to describe an antecedently existing reality. This is the idea that the world

\footnotetext{
${ }^{5}$ He merely says that it 'tell[s] us something true about the nature of truth' $(1997,128)$.
} 
comes first and our talk about it second; in other words, the way the world is takes explanatory priority over the semantic properties of our descriptions of it. This means that not only should we look for explanations of the truth-values of our assertions, but that we should be suspicious of explanations which don't refer to the way that pre-linguistic reality stands. For instance, we should be wary of accepting as fundamental an explanation of ' $p$ is true' that merely points out that another sentence is true. ${ }^{6}$ And we should equally wary of explanations that invoke entities we don't believe in. (Suppose a disbeliever in modal realism were to tell you: 'It is true that P is possible, because there is a possible world where P'. What kind of explanation would that be?)

\subsection{Demanding explanations: McFetridge's principle in action}

In this section I want to indicate how $\mathrm{E}$ can be used to argue against phenomenalism and Gilbert Ryle-type behaviourism. To begin with, recall that phenomenalists deny the existence of physical objects, paraphrasing statements about them into conjunctions of counterfactuals about experience. McFetridge's principle demands that phenomenalists explain why some sentences about physical objects are true. The realist about physical objects can do this by appealing to the properties of physical objects: "The book is square" is true because an independently existing lump of matter, the book, is square'. This route is closed to the phenomenalist, who doesn't believe in lumps of matter. The idealist's explanation, which will refer to the way that human minds are, will also be blocked. It seems there is nothing in the world for the phenomenalist to appeal to in explaining why true sentences about physical things are true. (For a more detailed argument along these lines, see Dancy 1985, 160-163.) This reasoning seems at least strong enough to put the burden of proof onto supporters of phenomenalism.

The argument against behaviorism runs parallel. The Rylean behaviourist claims that there are true counterfactuals about behaviour which have no 'categorical bases', and this cuts off the possibility of explaining these truths as we usually do: by mentioning mental properties.

\footnotetext{
${ }^{6}$ Explanations may refer to linguistic reality if the statements they explain are about language. For instance, if $p$ is ' $q$ is true' then it is fine to explain why $p$ is true by pointing out that $q$ is.
} 
McFetridge's principle presses the behaviourist for an explanation. But it is very hard to see what else there is to appeal to in accounting for the truth of these counterfactuals; we can certainly say that any explanation the behaviourist offers will have to be totally counterintuitive.

Standing back from these examples, we can see how $E$ operates as a constraint on theory-ontology pairs. Imagine that $\mathrm{P}$ is a sentence whose semantics are as follows:

$P$ is true iff $X$ (so $P$ is false iff not- $X$ ).

Since this is a statement about what it means for $\mathrm{P}$ to be true, we will be able to explain why $\mathrm{P}$ has the truth-value it does by saying whether X. But, in order to do justice to our intuitions, a satisfying explanation of why $\mathrm{P}$ is true must talk about the world: it must mention how some entities in our ontology stand. This acts as a constraint upon $\mathrm{X}$ : roughly speaking, $\mathrm{X}$ has to concern entities we take to exist. (This is why the sceptic about possible worlds can't rest content with possible worlds semantics.) So every claim in the theory must have implications for its ontology. McFetridge's principle challenges phenomenalists and behaviourists to produce a semantics of this sort. The burden lies with the theorist to explain exactly which parts of the world he or she is talking about.

\subsection{Explaining necessary truths}

As I hinted at the start of section 2.1, McFetridge's use of the notion of explanation allows him to sidestep the problems that the supervenience theories face when dealing with necessary truths. Exactly how does McFetridge escape the Restall's Refrigerator problem?

Remember that the problem arose when considering necessities, arithmetical truths for example. Supervenience theories which invoke classical entailment make it far too easy to provide a truthmaker for necessities.

On McFetridge's approach, the claim that truths have truthmakers is cashed out as a request to explain why true sentences are true. And it is clearly not the case that we can explain why the Goldbach conjecture is true (if it is!) by talking about refrigerators. We need to talk about the entities invoked by whatever is the right semantics for mathematical discourse. 
Platonists think this will be a realm of abstract objects; on their account, ' $2+2=4$ ' is true because the abstract objects 2 and 4 are related in a certain way.

Assuming that statements about God are noncontingent, and that they concern an eternal, infinite, aspatial (etc.) being, we will only be able to explain why 'God exists' has the truth-value it does by talking about this being - by saying, in fact, whether or not God exists. This is very different from the supervenience theories of truthmaking. According to Armstrong's theory, any entity will serve as truthmaker for 'God exists'. For all that the theories of Lewis and Bigelow say, 'God exists' might have no ontological implications at all. McFetridge's demand for explanation does not make truthmaking so easy.

Other responses to the problem of necessary truths drop the classical notion of entailment, using relevance logic instead (e.g. Restall 1996). McFetridge's solution has the virtue of not requiring such a change. That said, it does rely on the concept of explanation. Some people might hold that explanation is an unpleasantly murky or controversial concept, best excluded from our philosophical theories. In reply to this, I would claim that the confusion and controversy concern what it is to be an explanation; the notion itself is intuitively clear. After all, who could doubt that the truth of 'Grass is green' is explained by the colour of grass rather than the flavour of pineapples?

\subsection{Coda}

We have seen that McFetridge's principle is intuitively plausible, powerful enough to argue against behaviourism and phenomenalism, and immune to some of the difficulties faced by supervenience theories of truthmaking. I have not discussed Armstrong's truthmaker argument for an ontology of states of affairs, or whether $E$ is, or should be, capable of replicating it. But I hope I have said enough to indicate that McFetridge's theory is an alternative to the standard theories of truthmaking that merits further investigation. ${ }^{7}$

\footnotetext{
${ }^{7}$ Many thanks to the editors, Chris Hookway, Rosanna Keefe, Sue Lock, Esa Díaz-León, and an anonymous referee for all their helpful comments. And thanks also to audiences in Sheffield and at the Manchester conference.
} 
Works cited

Armstrong, D.M. 1989a. C.B. Martin, counterfactuals, causality, and conditionals. In John Heil (ed.) Cause, Mind, and Reality. Dordrecht: Kluwer.

Armstrong, D.M. 1989b. Universals: An Opinionated Introduction. Boulder, San Fransisco, London: Westview Press.

Armstrong, D.M. 1993. Reply to Martin. In John Bacon, Keith Campbell, Lloyd Reinhardt (eds.) 1993. Ontology, Causality and Mind. Cambridge: Cambridge University Press.

Armstrong, D.M. 1997. A World of States of Affairs. Cambridge: Cambridge University Press.

Bigelow, John 1988. The Reality of Numbers. Oxford: Clarendon Press.

Colyvan, Mark 2001. The Indispensability of Mathematics. Oxford: Oxford University Press.

Dancy, Jonathan 1985. An Introduction to Contemporary Epistemology. Oxford: Blackwell.

Dodd, Julian 1999. Farewell to states of affairs. Australasian Journal of Philosophy 77, 161-173.

Dodd, Julian 2000. An Identity Theory of Truth. Basingstoke: Macmillan Press.

Dodd, Julian 2002. Is truth supervenient on being? Proceedings of the Aristotelian Society 102, 69-86.

Gregory, Dominic 2001. Smith on truthmakers. Australasian Journal of Philosophy 79, 422-427. Horwich, Paul 1998. Truth (2nd. ed.). Oxford: Clarendon Press.

Lewis, David 1983. Modal Realism at work: properties. Repr. in D.H. Mellor and Alex Oliver (eds.) 1997. Properties. Oxford: Oxford University Press.

Lewis, David 1998. Papers in Philosophical Logic. Cambridge: Cambridge University Press.

Lewis, David 1999. Papers in Metaphysics and Epistemology. Cambridge: Cambridge University Press.

Lewis, David 2001. Truthmaking and difference-making. Noûs 35, 620-615.

McFetridge, lan 1977. Truth, correspondence, explanation and knowledge. In his Logical Necessity and Other Essays. London: Aristotelian Society 1990.

Oliver, Alex 1996. The metaphysics of properties. Mind 105, 1-80.

Oliver, Alex 1998. Review of Armstrong's A World of States of Affairs. Journal of Philosophy 95, 535-540.

Parsons, Josh 1999. There is no 'truthmaker' argument against nominalism. Australasian Journal of Philosophy 77, 325-334.

Quine W.V. 1969. Existence and quantification. In his Ontological Relativity. New York: Columbia University Press 1969.

Restall, Greg 1996. Truthmakers, entailment and necessity. Australasian Journal of Philosophy 74, 331-340.

Wright, Crispin 1992. Truth and Objectivity. Cambridge MA and London: Harvard University Press. 